\title{
Thermal Imaging and Physiological Analysis of Cold-Climate Caribou-Skin Clothing
}

\author{
Richard W. Hill, ${ }^{1}$ Glenn J. Tattersall, ${ }^{2}$ Kevin L. Campbell, ${ }^{3}$ Breanne Reinfort, ${ }^{4}$ Ana M. Breit, ${ }^{5}$ \\ Rick R. Riewe ${ }^{3}$ and Murray M. Humphries ${ }^{6}$
}

(Received 25 April 2019; accepted in revised form 5 November 2019)

\begin{abstract}
Protective clothing is essential for human existence in the Arctic, and caribou-skin clothing has played a pivotal role for millennia. Although people with northern experience often extol caribou-skin clothing, few scientific studies have investigated its properties. We used infrared thermal imaging in a pilot study to compare authentic caribou-skin clothing sewn by traditional Inuit seamstresses with two other types of cold-weather clothing: a standard-issue, Canadian army, winter uniform and an ensemble of modern retail clothing designed for extreme cold (a down anorak and snowmobile pants). To make the comparison, two subjects sequentially wore the three types of clothing — caribou skin, army uniform, and modern retail - in a still air, uniform thermal environment (where radiant temperatures of all environmental surfaces were equal to air temperature) at $-21^{\circ} \mathrm{C}$ to $-23^{\circ} \mathrm{C}\left(-6^{\circ} \mathrm{F}\right.$ to $\left.-10^{\circ} \mathrm{F}\right)$. Thermal imaging quantifies the temperature of the outer surface of clothing, thereby providing key, functionally relevant information on the interface where clothing and environment meet. Under otherwise similar conditions, a low clothing surface temperature indicates superior clothing performance and a reduced rate of heat loss from the body to the environment. Caribou-skin clothing was similar to modern extreme-cold retail clothing: the whole-body composite surface temperature of our subjects wearing caribou-skin clothing was $-22.1^{\circ} \mathrm{C}$ to $-22.7^{\circ} \mathrm{C}$, compared with $-21.6^{\circ} \mathrm{C}$ in both subjects wearing the modern retail clothing. The army winter uniform $\left(-18.9^{\circ} \mathrm{C}\right.$ to $\left.-20.0^{\circ} \mathrm{C}\right)$ was inferior. These quantitative results were mirrored by the subjects' subjective impressions. A particular advantage of thermal imaging is that it pinpoints locations in clothing where heat leaks occur. Although the two types of modern clothing exhibited heat leaks at zippered structures (even though fully closed), the caribou-skin clothing evaded such heat leaks by lacking such structures, because it is donned over the head. The integral hood characteristic of a caribou-skin parka was also superior in comparison to the detachable hood of the army uniform.
\end{abstract}

Key words: Arctic; circumpolar clothing; infrared thermography; Inuit; Rangifer tarandus; reindeer; skin clothing

RÉSUMÉ. Les vêtements de protection sont essentiels à l'existence humaine dans l'Arctique, et les vêtements en peau de caribou y jouent un rôle vital depuis des millénaires. Même si les gens qui ont évolué dans le Nord vantent souvent les mérites des vêtements en peau de caribou, peu d'études scientifiques ont été réalisées au sujet de leurs propriétés. Nous nous sommes servi d'imagerie thermique infrarouge dans le cadre d'une étude pilote visant à comparer les vêtements en peau de caribou authentique cousus par des couturières inuites traditionnelles à deux autres types de vêtements pour temps froid : un uniforme d'hiver standard de l'Armée canadienne et un ensemble de vêtements modernes du détail conçus pour des froids extrêmes (un anorak en duvet et des pantalons de motoneige). À des fins de comparaison, deux sujets ont porté, dans l'ordre séquentiel, les trois types de vêtements — vêtement en peau de caribou, uniforme de l'armée et vêtements modernes du détail — dans des conditions de vent nul thermique uniforme (où les températures radiatives de toutes les surfaces environnementales sont égales à la température de l'air) moyennant des températures allant de $-21{ }^{\circ} \mathrm{C}$ à $-23{ }^{\circ} \mathrm{C}\left(\mathrm{de}-6{ }^{\circ} \mathrm{F}\right.$ à $\left.-10{ }^{\circ} \mathrm{F}\right)$. L'imagerie thermique quantifie la température de la surface extérieure du vêtement, ce qui permet d'obtenir de l'information fonctionnellement pertinente et essentielle sur le point de rencontre du vêtement et de l'environnement. Dans des conditions par ailleurs semblables, la faible température du vêtement en surface indique un rendement supérieur pour ce vêtement et un taux réduit de perte de chaleur du corps à l'environnement. Les vêtements en peau de caribou ont donné des résultats semblables aux vêtements pour froid extrême modernes du détail : la température composite du corps entier de nos sujets portant les vêtements en peau de caribou variait de $-22,1{ }^{\circ} \mathrm{C}$ à $-22,7{ }^{\circ} \mathrm{C}$, comparativement à $-21,6{ }^{\circ} \mathrm{C}$ chez les deux sujets portant les vêtements modernes du détail. Les températures de l'uniforme d'hiver de l'armée étaient inférieures (de $-18,9{ }^{\circ} \mathrm{C}$ à $\left.-20,0{ }^{\circ} \mathrm{C}\right)$.

\footnotetext{
${ }^{1}$ Corresponding author: Department of Integrative Biology, Michigan State University, East Lansing, Michigan 48824, USA; hillr@msu.edu

${ }^{2}$ Department of Biological Sciences, Brock University, 1812 Sir Isaac Brock Way, St. Catharines, Ontario L2S 3A1, Canada

${ }^{3}$ Department of Biological Sciences, University of Manitoba, 50 Sifton Road, Winnipeg, Manitoba R3T 2N2, Canada

${ }^{4}$ Centre for Earth Observation Science, Department of Environment and Geography, 125 Dysart Road, University of Manitoba, Winnipeg, Manitoba R3T 2N2, Canada

${ }^{5}$ Department of Biology, University of Winnipeg, 515 Portage Ave., Winnipeg, Manitoba R3B 2E9, Canada; present address: Department of Biology, 5725 Murray Hall, University of Maine, Orono, Maine 04469, USA

${ }^{6}$ Natural Resource Sciences, McGill University, 21111 Lakeshore Road, Ste. Anne de Bellevue, Québec H9X 3V9, Canada

(C) The Arctic Institute of North America
} 
Ces résultats quantitatifs cadraient avec les impressions subjectives des sujets. Un des avantages particuliers de l'imagerie thermique, c'est qu'elle permet de repérer là où les pertes de chaleur se produisent dans les vêtements. Bien que les deux types de vêtements modernes perdaient de la chaleur à l'endroit des fermetures éclair (même si elles étaient fermées complètement), les vêtements en peau de caribou n'affichaient pas de telles pertes de chaleur en raison de l'absence de structures de ce genre parce que ces vêtements s'enfilent par la tête. Par ailleurs, il y a lieu de noter que la caractéristique intégrale du capuchon du parka en peau de caribou était également supérieure à celle du capuchon amovible de l'uniforme militaire.

Mots clés : Arctique; vêtement circumpolaire; thermographie infrarouge; Inuit; Rangifer tarandus; renne; vêtement en peau

Traduit pour la revue Arctic par Nicole Giguère.

\section{INTRODUCTION}

Temperature regulation is a fundamental challenge for all endotherms that defend a constant body temperature against colder environmental temperatures. In Arctic environments, where mammalian body temperature routinely exceeds air temperature by more than $60^{\circ} \mathrm{C}$ for extended periods, minimizing heat loss becomes critically important for energy conservation and survival. To this end, humans in the Arctic are highly dependent on clothing and other extrasomatic protections. In the 1950s, Scholander et al. (1950) and Hammel (1955) demonstrated by quantitative measurement that caribou skins are highly effective for insulating against heat loss. Later scientific studies emphasized that individual caribou hairs are composed of air-filled cavities (Timisjärvi et al., 1984; Meeks and Cartwright, 2005). Studies also suggested that the insulative value of caribou skins is relatively insensitive to wind and light moisture exposure (Cuyler and Øritsland, 2004). Circumpolar Indigenous peoples discovered the value of caribou skins centuries, probably millennia, earlier by their direct experience of living in Arctic cold (Issenman, 1997). Here, when we speak of caribou, we mean the species Rangifer tarandus, independent of alternative common names (e.g., reindeer) used to refer to the species in various parts of its range.

Northern people often live in a close socio-ecological relationship with caribou-a relationship that likely spans more than 10000 years (Velichko et al., 2017), possibly even 40000 years (Pavlov et al., 2001). This socio-ecological relationship centers on people's use of caribou as a staple food source, but importantly also includes non-food use of caribou in clothing and shelter (e.g., caribou-skin tents), as well as nonmaterial contributions of caribou to identity, knowledge, and well-being (Oakes, 1992; Issenman, 1997; King et al., 2005). Caribou-skin clothing is widely recognized as a central component of this socio-ecological relationship among Inuit and other North American peoples (Issenman, 1997; King et al., 2005; Pharand, 2012), as well as among other circumpolar peoples, including both Saami (Scholander et al., 1957; Issenman, 1997) and Chukchi (Oakes and Riewe, 1998). For many groups in the Eurasian Arctic (including Saami and Chukchi), the most common traditional dress in winter consists of two caribou skins covering the torso, the inner skin with fur facing in, the outer with fur facing out-identical in these respects to
Inuit clothing (Pharand, 2012). Regarding the specific question of how long Inuit and other North American groups have used animal-skin clothing, Issenman (1997) reviews the available archeological evidence (see also Pedersen, 2005). As she documents, the oldest preserved caribou-skin garments date to 500-700 years ago, and tools for preparation of skins and sewing of clothing occur at 4000 to 5000 year-old archeological sites. These findings document a long cultural association in which northern people have relied on caribou for one of their most urgent requirements: the need to stay warm in a severely cold environment.

Recognizing the importance of caribou-skin clothing for northern peoples, a premium should be placed on gaining a full scientific understanding of its properties, including not only the properties of the skins themselves, but also the design properties built into the clothing by the seamstresses who work within traditions established by centuries of experience. Issenman (1997) and Pharand (2012), among others, have documented the construction of the clothing. We are aware, however, of only two prior efforts to apply quantitative, scientific methods to analyze and document the functional value of caribou-skin clothing. One of these studies employed indirect inference (interpretation of the wearers' skin temperatures and self-reports of physical comfort) rather than making direct measurements on the garments (Oakes et al., 1995). The second study was a detailed scientific engineering analysis of a single aspect of the garments: the fur ruffs (typically made of wolverine or other suitable skins), often attached to caribou skins around the face (Cotel et al., 2004).

In the present research, we carry out a direct study of entire caribou-skin garments by use of thermal imaging (infrared thermography), a relatively new technology widely used for understanding the effectiveness of insulating structures, from houses to clothing (Watkins and Dunne, 2015; Tattersall, 2016). In studies of clothing, thermal imaging provides unique, spatially explicit insight because it identifies the exact physical locations of "heat leaks": places where heat travels especially easily from the body of a person, through their clothing, and into the cold environment.

During a study of clothing by thermal imaging, the thermography camera remotely measures - on a point-bypoint basis - the intensity of emission of infrared radiant energy from the outer-clothing surface. According to the 
Stefan-Boltzmann law, the intensity of infrared emission from a surface varies monotonically with the temperature of the surface (Campbell and Norman, 1998; Monteith and Unsworth, 2013). Thus, a point-by-point map of emission intensity can be converted to a point-by-point map of surface temperature: a thermal image, or thermal map. If a garment worn in a cold environment varies from place to place in its effectiveness as an insulator, its outer-surface temperature varies in tandem; garment surface temperature is lowest where the garment's insulative effectiveness is greatest (all other things equal) because body heat passes through the garment most slowly at such places (Watkins and Dunne, 2015; Tattersall, 2016). By studying an infrared thermal image of a garment therefore, an interested person can assess overall insulative effectiveness and identify the specific locations where heat is leaking relatively slowly or rapidly.

Here we take advantage of the availability of two authentic caribou-skin outfits, made by Inuit seamstresses using traditional methods, to carry out a pilot study in the application of infrared thermal imaging to improve understanding of traditional clothing. To our knowledge, caribou-skin clothing has never before been studied by thermal imaging. Thus, this study provides fresh insights into the properties of caribou-skin clothing, as well as a valuable background of experience for the design of future studies in which larger numbers of authentic outfits could be examined. The two caribou-skin outfits studied here (described in detail later) have been used by Rick Riewe and Jill Oakes for treks across the land and even as their sole shelter for winter nights spent in the Arctic wilderness at $-30^{\circ} \mathrm{C}$. In a research design similar to Oakes et al. (1995), we have compared these outfits to two other types of cold-weather clothing: an outfit of modern, high-quality retail clothing designed for extreme cold (duck-down anorak and insulated snowmobile pants) and a standardissue Canadian army winter uniform. Comparisons were carried out in severe cold, at a mean ambient temperature of approximately $-22^{\circ} \mathrm{C}$.

\section{MATERIALS AND METHODS}

\section{Study Environment and Equipment}

Studies were conducted in two adjacent temperaturecontrolled rooms: the $-22^{\circ} \mathrm{C}$ room and the $-15^{\circ} \mathrm{C}$ roomnamed for their nominal average temperatures - at the Centre for Earth Observation Science, University of Manitoba. Electronic equipment (including thermography camera) was set up in the $-15^{\circ} \mathrm{C}$ room, where the warmer temperature was suitable for the electronics. Subjects wearing defined clothing types occupied the $-22^{\circ} \mathrm{C}$ room. An insulated door connected the rooms. During studies, the door was opened and a sheet of $2.54 \mathrm{~cm}$ thick extruded polystyrene insulation (Owens Corning Foamular C-200) was pressure-fitted into the door opening. A small rectangle $(46 \mathrm{~cm} \times 56 \mathrm{~cm})$ of material was cut out of the polystyrene sheet, creating an open window that provided an uninterrupted line of sight between the camera and subjects. Images of the subjects in the $-22^{\circ} \mathrm{C}$ room could then be obtained with the thermography camera in the $-15^{\circ} \mathrm{C}$ room. The window was blocked when thermography images were not being obtained but opened for collection of thermography data.

To create a defined thermal environment for the subjects, a study arena was erected in the $-22^{\circ} \mathrm{C}$ room. The arena ( $2.8 \mathrm{~m}$ long $\times 2.1 \mathrm{~m}$ high and averaging $1.5 \mathrm{~m}$ wide) consisted of sheets of black cloth hung on a wood frame. With this design, the top, side walls, and back wall of the arena consisted principally of single sheets of free-hanging cloth, which equilibrated air temperature, establishing a uniform thermal environment (radiant temperature of all walls $\cong$ air temperature) inside the arena. The floor of the arena was covered with sheets of wood and plywood, on which subjects stood. The front of the arena, which faced the $-15^{\circ} \mathrm{C}$ room, was open, permitting the subjects to be viewed. During imaging, subjects stood in the arena at least $2 \mathrm{~m}$ from the sheet of polystyrene insulation separating the two rooms, meaning the subjects were $3-3.5 \mathrm{~m}$ from the thermography camera.

For thermography measurements we used a FLIR SC660 high-resolution thermography camera (FLIR Systems, Inc.). The camera had been factory calibrated within the preceding six months. Moreover, on each day of our study, its accuracy was verified by use of an Omega BB703 Blackbody Calibrator. The camera measured calibrator temperatures to within $\pm 0.5^{\circ} \mathrm{C}$.

Air temperature in the study arena was recorded every 5 min by a DS1922L-F5\#-ND iButton (accuracy: $\pm 0.5^{\circ} \mathrm{C}$ according to the manufacturer, Maxim Integrated Inc.) positioned $1.5 \mathrm{~m}$ above the floor. Air temperature averaged $-22.4^{\circ} \mathrm{C}$ (range: $-21.6^{\circ} \mathrm{C}$ to $-23.0^{\circ} \mathrm{C}$ ). Lighting inside the arena was subdued because the light from overhead fluorescent fixtures needed to pass through the sheets of black cloth to reach the arena interior. Lights were turned off during thermal imaging to eliminate reflected visible radiation. Fans mixed the air in the $-22^{\circ} \mathrm{C}$ room continuously to promote uniformity. The air inside the study arena, however, was virtually still (wind speed was measured as $0 \mathrm{~m} / \mathrm{s}$ with a Kestrel 4000 pocket weather tracker) because the cloth walls of the study arena impeded airflow from the surrounding room. Because of the stillness of the air, there was some settling of cold air in the arena, and temperature near the floor (detected by thermography) was sometimes as much as $2^{\circ} \mathrm{C}-3^{\circ} \mathrm{C}$ cooler than at chest height.

\section{Subjects and Experimental Design}

The study subjects were two adults, one female (termed subject 1; $162 \mathrm{~cm}$ tall; $60 \mathrm{~kg}$ body mass) and one male (subject 2; $170 \mathrm{~cm}$ tall; $70 \mathrm{~kg}$ ). Both are authors of this paper (A.M. Breit and K.L. Campbell) and thus played roles equal to other authors in designing the study. The experimental protocol was fully described to both individuals prior to 
initiating the study. Both were instructed that they could voluntarily withdraw at any time, and they provided both oral and written informed consent. To ensure safety, the two subjects co-occupied the study arena, and when they were in the arena, outside investigators checked with them frequently.

With three types of clothing to be investigated, each subject underwent three trials, with at least 3.5 hours between trials. During each trial, a strict, standardized protocol was followed by each subject, and each was timed individually. As already noted, the two subjects were in the study arena together during each trial. The timing of one was staggered by five minutes relative to the timing of the other, however, so that thermography of each subject could be carried out at a fixed time following the subject's entry to the arena.

During all trials, each subject wore a base layer of clothing consisting of a Mountain Equipment Co-operative (MEC) long-sleeved crew shirt and MEC long johns, both garments composed of $100 \%$ merino wool, T3 weight $\left(250 \mathrm{~g} / \mathrm{m}^{2}\right)$. Over the course of the study, each subject donned, in sequence, each of the three clothing types over the base layer. Henceforth, when we refer to "clothing" in the context of our experiments, we refer just to the outer garments that were donned over the base layer.

To monitor temperatures close to the body, each subject was equipped with two model DS1921H-F5\#-ND iButtons that were taped to the subject's skin and base layer at the front midline of the upper abdomen. One iButton, the skintemperature sensor, was positioned with its thermosensitive surface against the subject's skin, approximately over the xyphoid process, and taped in position with $3 \mathrm{M}$ Nexcare $^{\mathrm{TM}}$ adhesive tape. The second iButton, the innerclothing temperature sensor, was taped to the outside of the base-layer shirt $(\sim 3 \mathrm{~cm}$ below the first iButton) with its thermosensitive surface facing outward so as to make contact with the inner-clothing surface when clothing was worn. These iButtons recorded temperatures every two minutes. Because iButtons are small and log their data internally, they posed essentially no disruption to clothing or subjects.

Clothing was stored in the $-15^{\circ} \mathrm{C}$ room when not in use (caribou-skin clothing must be prevented from thawing between uses to protect its integrity). Immediately prior to the initiation of a trial, the clothing to be worn by each subject was brought to a cold changing room (air temperature: $1^{\circ} \mathrm{C}-2^{\circ} \mathrm{C}$ ), where the subject donned the clothing over a period of four to eight minutes. As soon as the clothing had been donned, the subject entered the study arena in the $-22^{\circ} \mathrm{C}$ room.

During a subject's first 50 minutes in the study arena, the subject was free to stand, move about, or sit on a chair (plastic) or stool (wood seat on metal legs). After 50 minutes, the subject-following the pre-determined protocol-stood continuously. Starting at the 55-minute mark, the subject held his or her arms continuously away from the torso (hands approximately $25 \mathrm{~cm}$ from the hips), and during this period the subject used a digital voice recorder to record subjective impressions of the clothing being worn (e.g., comfort, warmth). Investigators observed the thermography images continually, and starting at 60 minutes after the subject's entry to the study arena, thermography images were archived methodically over a period of approximately five minutes during which the subject sequentially faced the thermography camera, stood with the left side of the body toward the camera, faced away from the camera, and stood with their right side toward the camera. All data we report were gathered during this final data-gathering phase unless otherwise stated.

With the two subjects staggered in timing by five minutes during a trial, one entered the study arena five minutes after the other. Otherwise they were in the study arena together, enhancing safety. The subjects did not make physical contact. During thermal recordings, a suspended cloth in the arena ensured that direct radiative heat transfer could not occur between the two individuals. They exited the arena together after thermography had been completed on both.

\section{Clothing Details}

We studied two distinct caribou-skin outfits (Fig. 1) that, as detailed later, were sewn by two different seamstresses. One of the caribou-skin outfits had been sewn for a woman and was worn by subject 1 , whereas the other had been sewn for a man and was worn by subject 2 . In contrast, we used a single army winter outfit and a single modern retail outfit for extreme cold. Subjects wore these outfits during different trials (e.g., during the first trial, subject 1 wore the army outfit while subject 2 wore the retail outfit).

Each subject wore the same hand and foot clothing regardless of the outfit. That is, when we compared outfits, the differences from one to another were in the clothing for the parts of the body other than the hands and feet. Subject 1 always wore the hand and foot coverings associated with the woman's caribou-skin outfit; subject 2 always wore those for the man's caribou-skin outfit. The hand clothing (detailed later) extended up the forearm, and the foot clothing (also detailed later) extended up the calf. On his or her head, each subject always wore a wool tuque made in the style popularized in Pangnirtung, Nunavut (commonly known as a "Pang hat"). Each of the three outfits worn by a subject had an outfit-specific hood, which was pulled over the tuque.

The caribou-skin outfits (housed at the University of Manitoba) were hand-crafted by skilled Inuit seamstresses circa 1990 and have been lightly used and stored meticulously over the intervening years. In the traditional way, they were constructed of hand-scraped, untanned skins and have been preserved entirely by freezing when not in use (the numerous outfits kept in museums are not useful for functional research because of the chemical agents - usually arsenic — used to preserve them). During our studies, the outfits were complete: each consisted of a double-skin parka, a pair of trousers, and hand and foot 


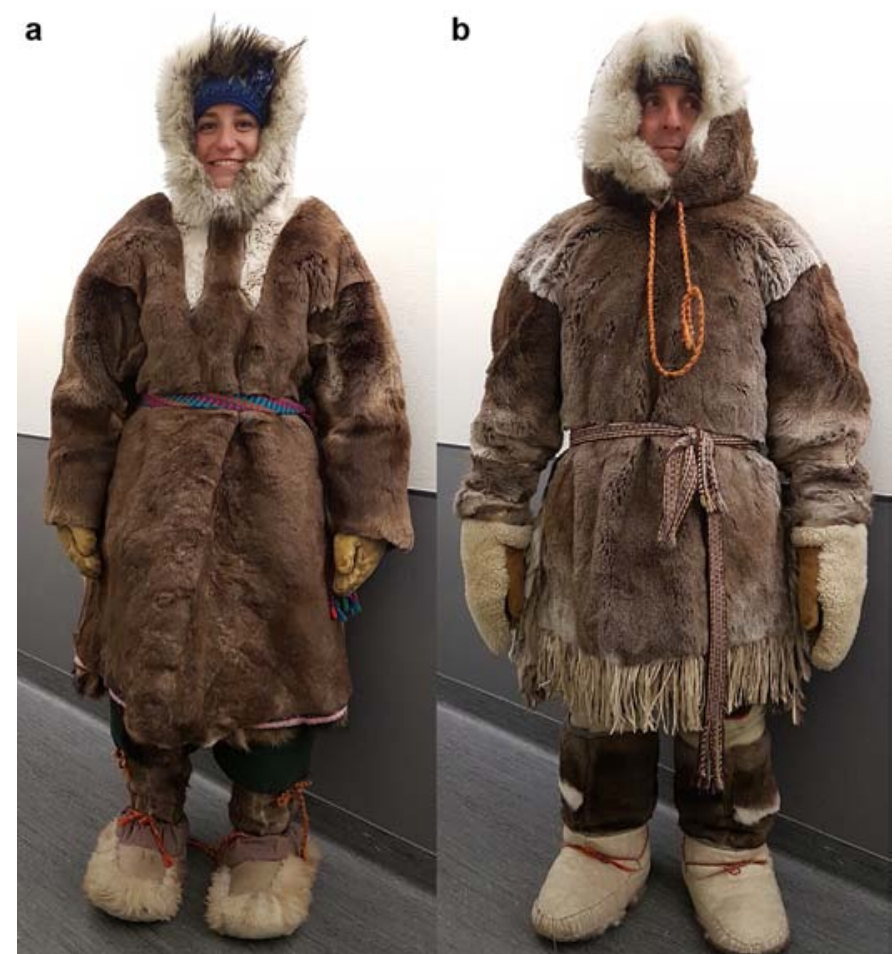

FIG. 1. Subjects wearing the two caribou-skin outfits. Subject 1 (a). Subject 2 (b). Each subject was similar in gender, height, weight, and body form to the individual for whom the outfit was made.

clothing, all of which were constructed entirely or mostly of skins. Regarding the parkas, both the man's and woman's were made of autumn-harvested caribou skins in Nunavut and designed to be donned by pulling them over the head. The woman's parka was made by June Klengenberg in the Kugluktuk community, while the man's was made by Ulayok Kaviok in the Arviat community. As noted, each parka consisted of two skins, not attached to one another and donned sequentially. The fur of the inner skin faced the subject's skin, whereas the fur of the outer skin faced outward (Fig. 1). A thin cotton anorak was worn between the two skins. The cotton cloth tended to be held in position by the skins on either side, making it easy to don and remove the skins and cloth ensemble as a unit. All four parka skins were hooded, knee-length, and had full-length sleeves (Fig. 1). For each parka, we measured the combined thickness of the inner and outer skins over the front midline of the subject's upper abdomen (i.e., over the iButtons) using a blunt 23-gauge needle, by inserting the needle through the fur of each skin and measuring the length of needle required. Both the woman's and man's outfits had provisions to impede flow of ambient air upward under the parkas at the lower edges. Specifically, the bottom margins of the man's inner- and outer-parka skins were trimmed with a fringe of narrow strips of fur-less caribou skin hanging down $12 \mathrm{~cm}$ (Fig. 1b) of a type traditionally used to impede airflow (see Issenman, 1997:122-129 for other examples of such fringes). The bottom margin of the inner skin of the woman's parka was trimmed with wolverine fur containing long guard hairs (again a device traditionally used to impede airflow). For similar reasons, the edges of the inner-skin hood surrounding the face were trimmed with Arctic wolf fur (Fig. 1) in both the woman's and man's parkas, and the openings of the sleeves at the wrists were trimmed with ruffs of wolverine fur (woman's) or wolf fur (man's). At waist height, each subject wore a sash (tied belt) around the parka (Fig. 1); in putting the sash on, subjects were instructed to tie it snuggly but not so tightly as to compress the caribou fur.

As for trousers, it is important to note that in this type of clothing, there is little direct exposure of the trousers to the outside air because the parkas hang approximately to the knees and the boots reach high on the lower legs (Fig. 1). Each pair of trousers consisted of a single untanned caribou skin. The man's trousers were made in the Siberian style, whereas the woman's were made in a style typical of the western Nunavut region. The fur faced outward on the man's trousers, inward on the woman's; the woman's trousers also had a layer of wind-blocking cloth sewn onto the skin. The legs of the man's trousers were full-length and tucked into the boots during our study. The legs of the woman's trousers hung low enough to overlap the upper boot edges by a few centimeters and were equipped with drawstrings in the lower hems (tied snuggly during our study).

Footwear (worn with all three clothing types) consisted of multiple layers of animal skins and knitted wool: four layers in the case of the man's, five in the woman's. In each case, one of the skin layers had a drawstring that was tied snuggly around the leg. Hand clothing for both subjects (worn with all three clothing types) consisted of two animal-skin layers, including a ruff around the opening. When a subject was dressed in caribou-skin clothing, the ruffs on the mittens contacted ruffs on the sleeves of the inner-parka skin, an arrangement that created a barrier to impede air movement up the sleeves.

The high-quality retail outfit designed for extreme cold consisted of a parka and trousers manufactured in the past decade and for sale to outdoor enthusiasts. The outfit - used for winter fieldwork during two winters in the Northwest Territories by author B. Reinfort-was in likenew condition. The parka was a Canada Goose ${ }^{\mathrm{TM}}$ Baffin Anorak (model 7505M), described by Canada Goose as a "super cold-weather, thigh-length anorak," which extended to upper-thigh length on our subjects. It was composed of a polyester/cotton shell and nylon plain-weave lining and filled with 625-fill-power white duck down. It was donned over the head, facilitated by a quarter-length, midline zipper at the neck that could be zipped down when donning the garment, plus a side zipper on one side. It had a wiresupported tunnel hood (lined at the front with fleece) with a coyote fur ruff surrounding the face. The parka was equipped with interior draw cords (tied snuggly) at the waist and lower hem, and it had recessed rib-knit cuffs and an elasticized snow skirt. The parka was put on over Go-Line $^{\mathrm{TM}}$ bib-style snowmobile pants with shoulder straps (manufactured in Manitoba, Canada). These pants were composed of a nylon shell and nylon liner, felt-lined in the 
TABLE 1. Temperatures and temperature differences (gradients) at the chest, following 60 minutes in the study environment. Temperature differences were calculated prior to rounding of measured temperatures, accounting for apparent discrepancies in some cases. Outersurface clothing temperature was measured by thermal imaging. Other temperatures were measured simultaneously with iButtons. Air temperature ranged from $-21^{\circ} \mathrm{C}$ to $-23^{\circ} \mathrm{C}$.

\begin{tabular}{|c|c|c|c|c|c|c|}
\hline \multirow{2}{*}{$\begin{array}{l}\text { Type of clothing } \\
\text { Subject }\end{array}$} & \multicolumn{2}{|c|}{ Caribou-skin } & \multicolumn{2}{|c|}{ Extreme-cold retail } & \multicolumn{2}{|c|}{ Canadian army winter } \\
\hline & 1 & 2 & 1 & 2 & 1 & 2 \\
\hline \multicolumn{7}{|l|}{ Temperature $\left({ }^{\circ} \mathrm{C}\right)$} \\
\hline Clothing outer surface & -23.3 & -22.8 & -22.1 & -22.6 & -19.8 & -19.1 \\
\hline Clothing interior surface & 29.1 & 29.1 & 30.2 & 29.8 & 27.3 & 29.2 \\
\hline Subject skin surface & 35.5 & 33.6 & 35.9 & 34.6 & 36.0 & 34.5 \\
\hline \multicolumn{7}{|l|}{ Temperature difference $\left({ }^{\circ} \mathrm{C}\right)$} \\
\hline Skin surface minus clothing interior surface & 6.3 & 4.6 & 5.8 & 4.8 & 8.7 & 5.3 \\
\hline Clothing interior surface minus clothing outer surface & 52.4 & 51.9 & 52.3 & 52.4 & 47.1 & 48.2 \\
\hline
\end{tabular}

seat and at the knees, and filled with Thinsulate ${ }^{\mathrm{TM}}$ insulation. The legs of the pants were full-length and pulled over the tops of the Inuit footwear.

The Canadian army standard-issue winter outfit consisted of clothing manufactured in the late 1990s: a "combat coat" (style W8466-5-PAOE) worn over "combat overalls" (style W8476-6-KS01). We obtained used items of this clothing in like-new condition from military surplus suppliers in Canada. The coat consisted of two parts: an outer nylon and cotton shell (polyester on the hood) lined with melton wool and an inner insulating garment composed of waffle-stitched nylon, filled with insulation ( $5 \mathrm{~mm}$ thick) that we identified as polyester fiber. The shell and insulating garment were held together by snaps and buttons. The shell had a flapcovered midline zipper along the entire length of the front; during our studies, the zipper was closed, and the flap was snapped shut over it. The coat was knee-length on our subjects, with a draw cord in the lower hem. It had an inbuilt (but detachable) hood, lined with melton wool $\left(375 \mathrm{~g} / \mathrm{m}^{2}\right)$, with a draw cord in the anterior margin, permitting the hood margin to be pulled tight, partially covering the face. The bib-style overalls (reaching mid-chest height) were held up by shoulder straps. Their construction was similar to the coat but thinner and more flexible: an outer nylon and cotton shell lined with melton wool, with an inner insulating garment (3 $\mathrm{mm}$ thick) composed of waffle-stitched material filled with polyester fiber. The legs of the overalls were fulllength and pulled over the tops of the Inuit footwear. Side zippers that extended from waist to lower hem on the legs were zipped as far over the footwear as possible without damaging the fur.

\section{Analysis of Thermal Images}

For calculations of surface temperature from the intensity of long-wave infrared emission, we assumed a surface emissivity of 0.98 (Monteith and Unsworth, 2013). For analysis of thermal images, we divided the body into defined regions (e.g., torso, arms). For each region, we used Image $J$ to determine 1) the mean and standard deviation (SD) of surface temperature (measured as the mean and $\mathrm{SD}$ of all pixel-specific temperatures in the region) and 2) region area (measured as number of pixels in the region). To obtain whole-body mean temperatures - combining all regions together-we calculated the weighted mean of the regions, each region weighted by its area.

\section{RESULTS}

For quantifying the insulation provided by a material, one of the most relevant measures is the difference in temperature the material maintains from one side of the material to the opposite side. We measured this difference in the chest region (front midline of the upper abdomen, approximately over the xyphoid process). A unique advantage provided by thermal imaging is that it remotely (without contact) measures the temperature of the outer surface of a garment. As summarized in Table 1, we simultaneously measured the clothing's outer-surface temperature and, using iButtons, the temperatures at the clothing's interior surface and the skin surface. These measures were made following a 60-minute exposure to ambient conditions in the study arena: a time period during which all measured variables came to steady-state. For both subjects, and in all types of clothing, chest-skin temperature ranged only from $33.6^{\circ} \mathrm{C}$ to $36.0^{\circ} \mathrm{C}$ (Table 1). The difference in temperature between the clothing's outer surface and the clothing's interior surface was similar $\left(51.9^{\circ} \mathrm{C}-52.4^{\circ} \mathrm{C}\right)$ when the caribou skin and extreme-cold retail clothing were worn (Table 1). However, a smaller temperature difference $\left(47.1^{\circ} \mathrm{C}-48.2^{\circ} \mathrm{C}\right)$ was maintained by the army winter uniform.

Regarding the caribou-skin clothing, the combined thickness of the inner- and outer-parka skins in the chest region (based on 10 measurements per skin) was $41 \mathrm{~mm}$ in subject 1 and $39 \mathrm{~mm}$ in subject 2. During these measurements, no effort was made to fluff the fur (which, as always during this study, was simply permitted to assume its natural contours). In both parkas, the thickness of the outer-skin fur was greater than the inner: the outerskin fur accounted for $55 \%-62 \%$ of total thickness.

Figure 2 presents full-body thermal images of each subject, seen from the front, wearing each of the three types 


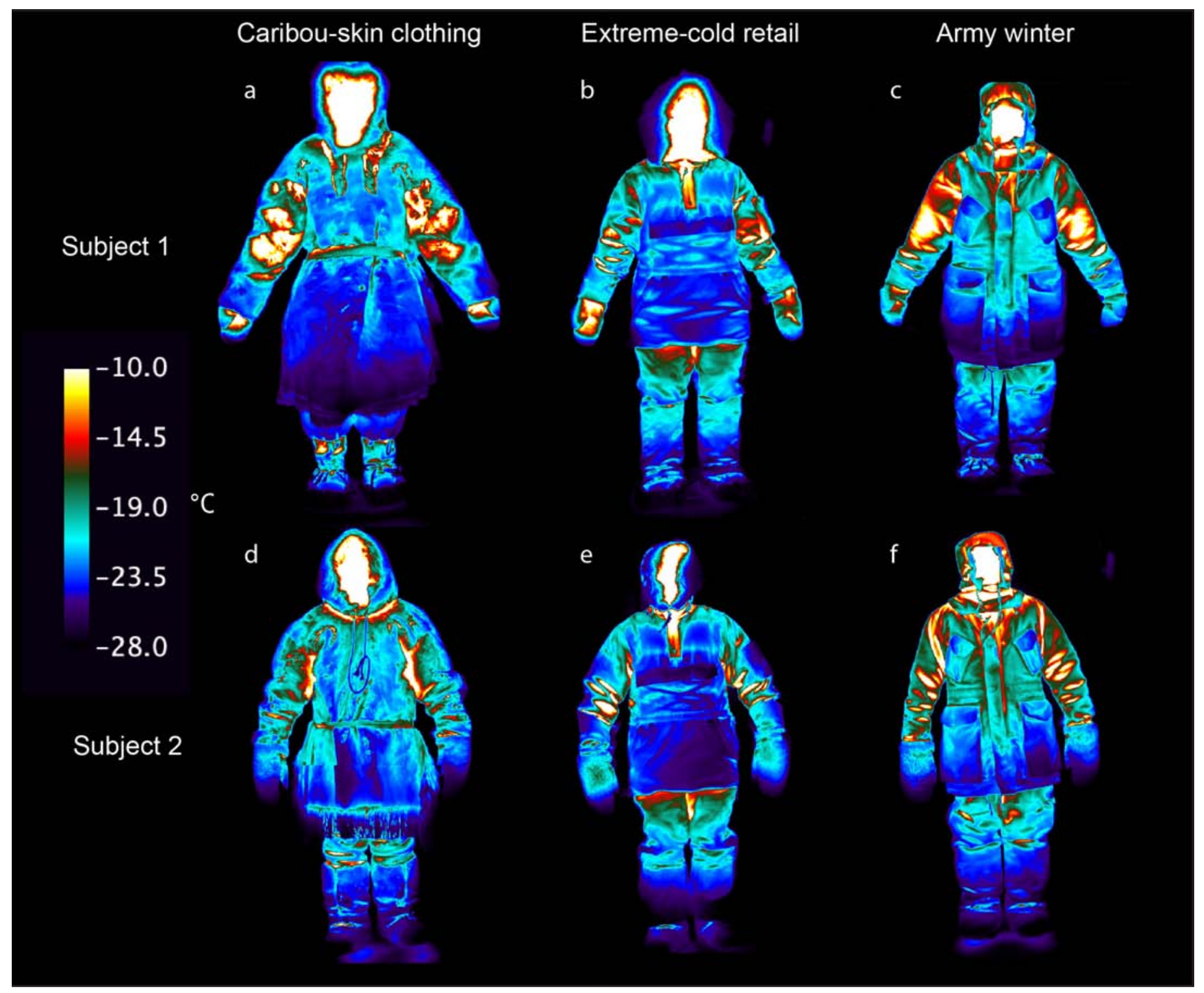

FIG. 2. Front full-body thermal images of the two subjects in the three types of clothing studied, showing location-specific surface temperature in false colour. False colours are calibrated at the left of the image by the vertical scale, which shows the range of false colours used and the manner in which colours correspond to temperatures. Each image was produced by combining two wide-view images (upper and lower body) recorded during a five-minute period following 60 minutes in the study environment. Subjects had been standing for 10 minutes prior to the five-minute recording period. During the second half of the 10 -minute period, they started holding their arms away from their bodies. Both subjects wore the same extreme-cold retail clothing at different times. They also wore the same army winter clothing. However, they wore different caribou-skin clothing. High surface temperatures directly within the armpit areas need to be interpreted with caution, because if the arms were unintentionally allowed to press against the torso for a period, the closely opposed torso and arm surfaces would have warmed by heat accumulation; when the arms were then held away, the warm surfaces would have become visible. In Figures $2 \mathrm{~b}$ and $2 \mathrm{e}$, the areas of relatively high surface temperature immediately below the anorak probably resulted from compression of the trousers by the tied drawstring in the lower anorak hem.

of clothing. The temperature of the outer surface of the clothing is shown in false colour, calibrated as shown by the scale at the left of the image. Other things equal, a relatively low temperature at the outer clothing surface signifies a relatively low rate of heat flux to the clothing surface from the body and therefore relatively high clothing insulation. Figure 3 presents full-body thermal images of the subjects seen from behind.

Table 2 summarizes the average surface temperatures of particular body regions. These data were extracted from close-up thermal images taken concurrently with the wide-view images in Figures 2 and 3. In Table 2, only body regions that were covered by material specific to clothing type are included (i.e., regions covered with footwear or hand wear are excluded). The front of the head is excluded because the face was not covered with clothing.

From Table 2, we calculated a composite (whole-body) measurement of the outer-surface temperature of the clothing for each clothing type: composite in the sense of including all body regions covered with material specific to the clothing type. The composite measures included the sides and back of the head, and the fronts and backs of the torso, arms, and the upper-leg areas. As seen in Table 3, the composite surface temperature was between $1.6^{\circ} \mathrm{C}$ and 


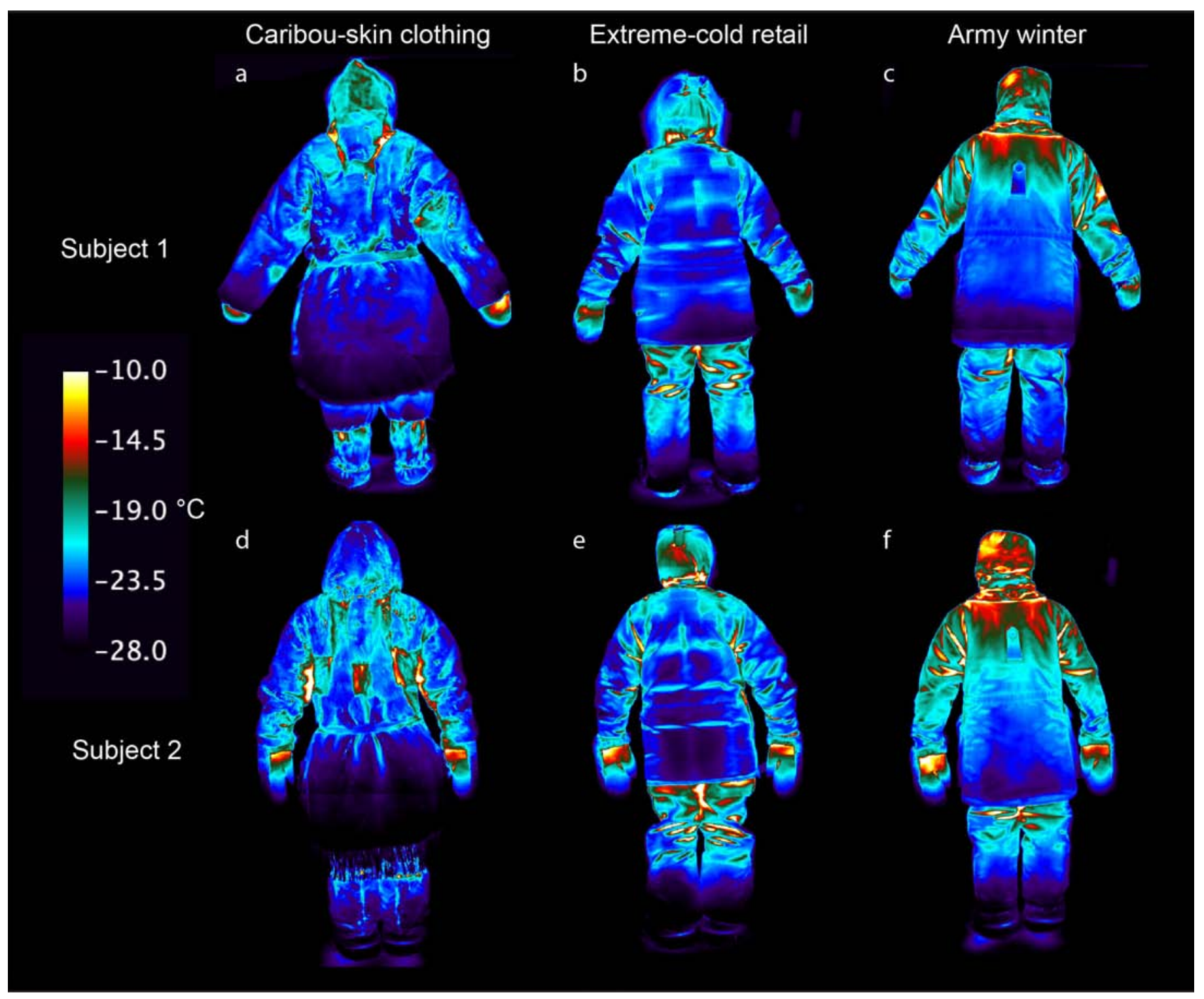

FIG. 3. Back full-body thermal images of the two subjects in the three types of clothing studied, showing location-specific surface temperature in false colour. See caption of Figure 2 for detail.

$2.7^{\circ} \mathrm{C}$ higher when the army winter clothing was worn than when the extreme-cold retail clothing was worn, and $0.5^{\circ} \mathrm{C}-1.1^{\circ} \mathrm{C}$ higher when the latter was worn than when the caribou-skin clothing was worn.

Inspection of Figures 2 and 3 draws attention to a number of specific clothing features that are of concern for optimizing clothing effectiveness. As we discuss these features in the numbered paragraphs below, we occasionally use the term "heat leak," which refers to an area where the outer-surface temperature of the clothing is sharply higher than in the immediately adjacent areas. The term "heat leak" refers to the fact that a locally high rate of heat flux to the clothing surface is required for an area to exhibit a high surface temperature.

1. The types of torso clothing that open down the front midline (to be put on or taken off) exhibited heat leaks along the midline. The extreme-cold retail clothing parka had a quarter-length zipper at the top. Figures $2 b$ and $2 \mathrm{e}$ show that this zipper construction created a heat leak even when the zipper was closed. In the army clothing, the coat opened by way of a full-length, flap-covered zipper. As seen in Figures $2 \mathrm{c}$ and $2 \mathrm{f}$, this construction caused heat leaks even when closed, especially in the upper body near the neck. In contrast, as seen in Figures 2a and 2d, the traditional caribou-skin parkas exhibited none of the local, midline heat leaks displayed by the other clothing types because the parkas (donned over the head) consisted of uninterrupted caribou skins along the midline.

2. Where the parka of caribou-skin clothing hung below the waist, it provided additional insulation for the hips and upper legs, as seen by comparing Figures $2 \mathrm{a}$ and $2 \mathrm{~b}$, or by comparing Figures $3 \mathrm{~d}$ and $3 \mathrm{e}$ (in both of these comparisons one subject is seen with and without the upper legs covered by a lengthy parka). 
TABLE 2. Regional outer-surface temperature of clothing (mean, standard deviation in parentheses) when subjects wore each of the three types of clothing. Data are extracted from close-up thermal images. "Upper-leg area" refers to the leg above the knee (up to the lower edge of the parka in the extreme-cold retail clothing), whether the leg itself was visible or covered by upper-body clothing. Data for arm and leg are from the left arm and left leg. In the side (profile) images of the head, only clothing (not face) was visible.

\begin{tabular}{|c|c|c|c|c|}
\hline \multirow[b]{2}{*}{ Body region } & \multirow[b]{2}{*}{ Subject } & \multicolumn{3}{|c|}{ Type of clothing } \\
\hline & & Caribou-skin & Extreme-cold retail & Canadian army winter \\
\hline Head-back & $\begin{array}{l}1 \\
2\end{array}$ & $\begin{array}{l}-22.6(1.7) \\
-19.9(1.9)\end{array}$ & $\begin{array}{l}-18.3(3.2) \\
-21.1(2.6)\end{array}$ & $\begin{array}{l}-15.6(2.5) \\
-17.9(2.6)\end{array}$ \\
\hline Head-left side & $\begin{array}{l}1 \\
2\end{array}$ & $\begin{array}{l}-18.0(3.5) \\
-21.6(1.8)\end{array}$ & $\begin{array}{l}-19.1(3.4) \\
-17.4(3.4)\end{array}$ & $\begin{array}{l}-17.1(3.4) \\
-13.4(3.1)\end{array}$ \\
\hline Head-right side & $\begin{array}{l}1 \\
2\end{array}$ & $\begin{array}{l}-17.7(2.6) \\
-20.9(2.3)\end{array}$ & $\begin{array}{l}-18.9(4.0) \\
-18.9(3.9)\end{array}$ & $\begin{array}{l}-17.1(2.7) \\
-15.3(3.9)\end{array}$ \\
\hline Torso-front & $\begin{array}{l}1 \\
2\end{array}$ & $\begin{array}{l}-20.9(2.5) \\
-21.3(2.8)\end{array}$ & $\begin{array}{l}-23.5(2.9) \\
-22.7(2.6)\end{array}$ & $\begin{array}{l}-19.4(3.6) \\
-20.6(3.0)\end{array}$ \\
\hline Torso-back & $\begin{array}{l}1 \\
2\end{array}$ & $\begin{array}{l}-22.5(2.8) \\
-22.7(2.2)\end{array}$ & $\begin{array}{l}-23.6(2.1) \\
-23.8(1.5)\end{array}$ & $\begin{array}{l}-20.5(3.1) \\
-21.7(2.9)\end{array}$ \\
\hline Arm-front & $\begin{array}{l}1 \\
2\end{array}$ & $\begin{array}{l}-19.5(2.9) \\
-20.2(3.8)\end{array}$ & $\begin{array}{l}-19.8(4.3) \\
-18.3(3.8)\end{array}$ & $\begin{array}{l}-16.0(3.5) \\
-14.3(6.7)\end{array}$ \\
\hline Arm-back & $\begin{array}{l}1 \\
2\end{array}$ & $\begin{array}{l}-22.7(2.1) \\
-23.4(1.9)\end{array}$ & $\begin{array}{l}-22.5(2.8) \\
-22.9(2.0)\end{array}$ & $\begin{array}{l}-19.1(3.2) \\
-20.1(2.8)\end{array}$ \\
\hline Upper-leg area-front & $\begin{array}{l}1 \\
2\end{array}$ & $\begin{array}{l}-22.2(3.1) \\
-25.5(1.1)\end{array}$ & $\begin{array}{l}-19.9(3.1) \\
-19.7(2.1)\end{array}$ & $\begin{array}{l}-19.8(2.6) \\
-21.3(1.7)\end{array}$ \\
\hline Upper-leg area-back & $\begin{array}{l}1 \\
2\end{array}$ & $\begin{array}{l}-26.4(2.5) \\
-26.0(1.3)\end{array}$ & $\begin{array}{l}-18.9(3.6) \\
-19.4(2.8)\end{array}$ & $\begin{array}{l}-19.4(3.4) \\
-21.1(2.5)\end{array}$ \\
\hline
\end{tabular}

3. In all three types of clothing, the locations where the hood was joined to the torso clothing were weak spotssites of heat leaks. In the army winter clothing - the only clothing with a detachable hood-these locations were particularly conspicuous in the thermographic images, signaling especial vulnerability to heat loss as seen in Figures $2 \mathrm{c}$ and $2 \mathrm{f}$ and Figures $3 \mathrm{c}$ and $3 \mathrm{f}$.

4. Focusing on hood performance, the hoods of the caribouskin outfits and the hood of the Canada Goose parka were approximately equal in effectiveness, as judged by outside surface temperature (Fig. 2a, b, d, e; Fig. 3a, b, d, e; Table 2). However, the hood of the army winter clothing was markedly inferior (Fig. 2c, f; Fig. 3c, f; Table 2).

5. For subjects wearing the caribou-skin and extreme-cold retail clothing, the outer surface of the hood (see Table 2) was far colder than the surface of the face (average face surface temperature was $+19^{\circ} \mathrm{C}$ ). This distinction is important because the rate of heat loss to the environment (per $\mathrm{cm}^{2}$ of surface area) is a positive function of the difference between surface temperature and environmental temperature. Whereas the surface of the face was approximately $41^{\circ} \mathrm{C}$ warmer than environmental temperature, a difference that promoted a high rate of heat loss, the hood outer-surface temperature was less than $5^{\circ} \mathrm{C}$ warmer than the environmental temperature. Recognizing the disparity of these gradients, there was a great advantage to pulling the front edges of the hood over as much of the face as possible (while allowing the moisture expelled by breathing to escape). The same conclusions apply to the army clothing, but with a smaller quantitative advantage because the hood of the army clothing had a higher outer-surface temperature (Table 2).
TABLE 3. Composite (whole-body) mean temperature $\left({ }^{\circ} \mathrm{C}\right)$ of the outer clothing surface for each of the three types of clothing, encompassing all regions of the body covered with clothingspecific material. Footwear, hand wear, and face are excluded.

\begin{tabular}{lccc}
\hline \hline \multirow{3}{*}{ Subject } & \multicolumn{3}{c}{ Type of clothing } \\
\cline { 2 - 4 } & Caribou-skin & Extreme-cold retail & Canadian army winter \\
\hline 1 & -22.7 & -21.6 & -20.0 \\
2 & -22.1 & -21.6 & -18.9 \\
\hline \hline
\end{tabular}

6. The inner-arm surfaces (Fig. 2) were areas of high vulnerability to heat leak in all three types of clothing. The patchy heat leak areas on the inner arms (Fig. 2) arose because of the dynamics of flexing and extending the arms at the elbow joint. For people wearing fur clothing, when the arms were extended, "splits" (gaps) in the fur often opened up between adjacent fully furred areas (a phenomenon also seen sometimes in living mammals with coarse fur). For people wearing the torso garments constructed with down fill or fiber fill (i.e., extreme-cold retail clothing, army winter clothing), repeated arm movements caused the fill to shift, creating areas of high and low fill. The splits in the fur or the areas of low fill created heat leaks (Fig. 2). Because of these leaks, as Table 2 shows, the inner-arm (front) surfaces always exhibited a higher average surface temperature than the outer-arm (back) surfaces when measured at the same time in the same person. The distinction between the front and back arm surfaces is also evident when Figures 2 and 3 are compared.

7. When the caribou-skin parka worn by subject 1 was made, the seamstress included two decorations on the front of the outer skin (Fig. 1a). These consisted of strips 
of light-coloured caribou fur on either side of the neck, which contrasted with the brown colour of most of the fur. The decorations are visible in the thermal image of subject 1 (Fig. 2a), evidently because the fur of the decorations provided less insulation than the rest of the fur and, also, narrow heat leaks occurred along the seams between the two types of fur. We found that 1) the average surface temperature over the decorations was $5.9^{\circ} \mathrm{C}$ higher than the average surface temperature over the rest of the front torso, and 2) the decorations (factoring in their areas) raised the overall front torso surface temperature by about $0.4^{\circ} \mathrm{C}$ relative to what it would have been without them.

8. Where fluffy insulation is compressed, its insulative value is typically reduced. This phenomenon likely explained the heat leaks that existed (Fig. 2a, d) next to and along the sash (belt) tied at the waist in the caribouskin clothing.

Near the end of each one-hour trial in the $-22^{\circ} \mathrm{C}$ room, each subject recorded a subjective narrative report of comfort and clothing effectiveness. Subject 1 did not report dramatic differences among clothing types. Her opinion was that her head, arms, torso, and upper legs were basically warm in all three clothing types. However, she reported feeling a bit "cooler and less comfortable" in the army winter clothing than in the other types. In regard to her hands, feet (which were clothed in the standard hand wear and footwear) and face, she reported cold fingers, toes, and nose in all three clothing types, with no sure differences among types. Subject 2 did not always mention cooling of hands and feet, and face, but when he did, the cooling he reported was subtle compared to that reported by subject 1. Thus, subject 2 took more of a whole-body approach to describing his experience. Comparing the caribouskin and army winter clothing, he reported a dramatic difference, saying the caribou-skin clothing was "far better" and "a lot warmer" for all parts of his body, even though he was basically warm in the army outfit. When wearing the caribou-skin clothing, he said he sometimes felt on the verge of sweating, whereas in the army clothing, he reported a touch of chill in places. Subject 2 reported that the extreme-cold retail clothing was warm virtually everywhere, but slightly cooler and less comfortable than the caribou-skin clothing, and he never felt on the verge of sweating in the retail clothing.

\section{DISCUSSION}

This study is the first application of infrared thermal imaging to enhance understanding of traditional caribouskin clothing. The images generated by thermography provide entirely novel insights, showing in detail where the clothing is vulnerable to heat leaks and where it provides especially effective insulation for the body (Watkins and Dunne, 2015; Tattersall, 2016). Study by thermography also quantifies, in an entirely novel way, the surface temperatures of the clothing (Tables 1-3; Figs. 2 and 3). That is, such study quantifies the temperatures that prevail at the interface between the clothed body and the surrounding environment-temperatures of key importance for analysis of rates of heat exchange (Campbell and Norman, 1998; Monteith and Unsworth, 2013). None of this information has before been available. Thus, this study provides many fresh insights. On the other hand, sample sizes are limited, which is typical of pilot studies. Later studies with large sample sizes will hopefully follow and provide statistically more robust insights. This study will help guide the choice of experimental designs in such future research.

All the measurements gathered in this research point to traditional caribou-skin clothing as being similar to or slightly superior to modern extreme-cold retail clothing in its ability keep a sedentary person warm in still air at $-22^{\circ} \mathrm{C}$. Whether our subjects wore the caribou-skin clothing or the extreme-cold retail clothing, the temperature difference between the inner and outer clothing surfaces was closely similar $\left(51.9^{\circ} \mathrm{C}-52.4^{\circ} \mathrm{C}\right)$ (Table 1). Average whole-body outer-clothing surface temperature-our most rigorous measure of overall clothing insulation-was slightly lower with caribou-skin clothing $\left(-22.1^{\circ} \mathrm{C}\right.$ to $-22.7^{\circ} \mathrm{C}$ in the two subjects) than with modern extreme-cold retail clothing $\left(-21.6^{\circ} \mathrm{C}\right.$ in both subjects), values indicating close similarity, but possibly a slight reduction in the rate of heat loss with the skin clothing (Table 3). Congruently, in their narrative reports, one of our subjects rated the caribou-skin clothing as being slightly warmer and more comfortable than the extreme-cold retail clothing, whereas the other rated them equal. Larger sample sizes will be required to determine if there is a statistically significant difference between the traditional and modern clothing types.

A question that arises is how well the quantitative measures provided by thermography relate to perceived comfort. One important observation can be made from our data. The average whole-body outer-clothing surface temperature for the army winter clothing was $-18.9^{\circ} \mathrm{C}$ to $-20.0^{\circ} \mathrm{C}$ : that is, $2^{\circ} \mathrm{C}-3^{\circ} \mathrm{C}$ higher than the values seen for the caribou-skin and retail clothing (Table 3). Simultaneously, our two subjects reported that the army clothing was clearly inferior to the other clothing types in keeping them warm. Thus, in terms of perceived comfort, people notice a difference in clothing effectiveness that results in a $2^{\circ} \mathrm{C}-3^{\circ} \mathrm{C}$ difference in surface temperature.

The images provided by infrared thermography (Figs. 2 and 3) provide spatially explicit insight into the physical locations of heat leaks. Along the front torso midline, the images in Figure 2 provide direct visual confirmation that traditional caribou-skin parkas, which lack a front opening and are donned over the head, avoid the heat leaks seen in modern types of clothing that have a front zipper or other type of front opening. Traditional Inuit parkas hang well below the waist and often have elongated, hanging flaps of skin at the front, back, or both (Issenman, 
1997; King et al., 2005). The images in Figures 2 and 3 provide direct visual confirmation that thermal advantages accrue from having the hips and upper legs covered by the parka skins (e.g., compare Figure 2a, where the thighs are covered by parka skins, with Figure $2 b$, where the thighs of the same subject are not covered by parka skins; or compare Figures $3 \mathrm{~d}$ and $3 \mathrm{e}$ ). All three types of clothing studied have a hood. The thermal images document that a hood dramatically lowers the outer-surface temperature on the head by approximately $40^{\circ} \mathrm{C}$ relative to the surface temperature of bare head skin (e.g., bare face) (Fig. 2). The hood of caribou-skin clothing is equal to or superior to hoods in modern dress, in part because it is sewn integrally into the parka, evading dramatic heat leaks that may occur with a detachable hood (e.g., compare Figures $2 \mathrm{a}$ and $2 \mathrm{~d}$ with Figures 2c and 2f, and compare the analogous back views), but note that the join between hood and parka is a spot where heat leaks might be reduced even further in caribou-skin clothing.

An unexpected revelation evident in our images is that decorations can slightly reduce the thermal protectiveness of a caribou-skin garment (Fig. 2a). Decorations are common (Issenman, 1997; King, 2005). They may have cultural or spiritual significance, or they may be included for more practical reasons such as identifying the seamstress or permitting fellow travelers to easily recognize each other in fog or snow (Issenman, 1997; R. Riewe, pers. observ.).

Another spatial insight provided by our thermography images is that the inner arms are potentially serious weak areas, rife with heat leaks (Fig. 2). This is true of all three types of clothing investigated and suggests that special attention to the insulative integrity of the inner arms could significantly improve the performance of cold-weather clothing.

Physiologists recognize that in all clothing, the single most important determinant of the thermal insulation provided is the amount of still air maintained between body and environment: effective cold-weather clothing, regardless of type, functions by creating pockets of still air (Burton and Edholm, 1955; Cena and Clark, 1978). The individual hairs of caribou are "hollow": constructed internally of a bubble-wrap-like matrix of microscopic air pockets in which the air is still (Timisjärvi et al., 1984; Meeks and Cartwright, 2005). At a larger scale, all commentators stress that when caribou-skin clothing is sewn in a traditional way by Inuit seamstresses, it fits the intended wearer in a deliberately loose way (Issenman, 1997). The loose fit is important in part because it ensures that macroscopic still-air spaces are fully expanded (rather than compressed), which increases the insulative value of the pelts. As the thermal images in Figures $2 \mathrm{a}$ and $2 \mathrm{~d}$ show, compression of pelts by a sash (belt) can potentially decrease insulative effectiveness, creating heat leaks.

During the Cold War (with its fears of Arctic military conflict between the great powers), teams of highly qualified thermal scientists discussed caribou-skin clothing as a model for designing the most high-performance Arctic clothing possible (see transcript in Rodahl, 1958). To estimate the effectiveness of caribou-skin clothing, they used rigorous measures of the insulation of caribou skins obtained with laboratory apparatus (Scholander et al., 1950; Hammel, 1955). Those measures - which have not been superseded-employed patches of caribou skin (about $28 \mathrm{~cm}$ diameter in Scholander et al., 1950, and about $10 \mathrm{~cm}$ diameter in Hammel, 1955) cut from the animal's back. In Scholander et al. (1950), the fur was "ruffed up" to be as thick as possible during measurement. The exacting laboratory measures of skin-patch insulation suggested that clothing of extraordinary performance-combining exceptional insulation and mobility - could be designed using caribou-skin clothing as a model (Rodahl, 1958). The physiological data now available on actual caribouskin clothing (Oakes et al., 1995; Cotel et al., 2004; this study) are not of the type needed for a direct comparison with the predictions made from the laboratory measures on skin patches. Nonetheless, the physiological studies seem clearly to make two points. First, caribou-skin clothing is a superior type of clothing in the Arctic. Second, however, caribou-skin clothing is probably not as extreme in its performance as the predictions made for it (Rodahl, 1958).

This divide between performance and prediction is an important area for future research, in which physiologists will need to marshal a concerted effort to understand the individual "pieces of the puzzle" (e.g., the detailed properties of skins) and integrate this information quantitatively to obtain a full understanding of how the pieces work together to produce the properties of traditional caribou-skin outfits. For this undertaking, one important consideration is skin variation, both among and within skins. A single skin is not uniform in its properties; thus, data for a patch of back skin cannot be extrapolated to full pelts (Timisjärvi et al., 1984; Johnsen et al., 1985). Another important consideration is that the thermal insulation of pelts is not the sole criterion used by northern people to select clothing materials (Oakes et al., 1995; Issenman, 1997). The responses of pelts to water (and water condensation) have an equal claim to importance for people living in natural outdoor environments. When exposed to water or water condensation, many nontraditional clothing materials, such as down and wool, exhibit one or both of two potentially fatal flaws: absorption of water and, when wet, resistance to shedding absorbed water (Issenman, 1997). Caribou fur and a number of other furs, in sharp contrast, do not absorb water readily; moreover, if ice forms in them from condensation or brief water immersion, the problem can be solved by wiping or physically beating skins to break ice crystals off (Oakes, 1992; Issenman, 1997). These properties are of intrinsic value regardless of thermal insulation. Besides thermal insulation and water responses, another important criterion Inuit use in choosing clothing materials is bulk: a material's weight and its potential to interfere with body movements. Northern people do not always select the thickest, most insulating 
skins for their clothing (Oakes and Riewe, 1998; Pharand, 2012). Moreover, they sometimes shorten the fur on a skin to make the skin more suitable in biomechanical properties (R. Riewe, pers. observ.).

Of course, in our study, all of our conclusions regarding the relative performance of the three clothing types investigated are contingent on the study conditions we employed. An important question for future research is whether freshly made caribou-skin clothing might be superior or inferior to carefully maintained but older clothing. Also, how do the three clothing types compare in wind or during short- or long-term physical exercise?

Modulation of caribou-skin clothing insulation is another central question awaiting better understanding. Traditionally, Inuit hunters were out on the land for long continuous periods of many hours or days, dressed only in their caribou-skin clothing. Sun, wind, air temperature, and exercise intensity could vary widely over time; a hunter needed to adjust the insulation of his clothing up or down without the luxury of possessing multiple sets of clothing and changing from one to another. From a physiological point of view, methods for adjusting clothing insulation are as important and interesting as the question of insulation itself. Nonetheless, up to now physiologists have almost entirely neglected the mechanisms of modulating clothing insulation. In fact, none of the potential mechanisms has been quantified in the slightest degree. Thus, when we consider future research directions, the study of these mechanisms is another top priority.

With these thoughts in mind, we have focused on the methods that Inuit use to modulate the insulation of caribou-skin clothing even as they wear the clothing continuously. Through interviews and reading (e.g., King, 2005), we have assembled a short list of such methods:

Modulation of the chimney effect: Traditional caribouskin clothing is constructed in ways that permit warm air under the clothing to rise toward exit passages and be replaced by fresh air entering from below (Folk, 1966; Issenman, 1997). Such air movement is an important aspect of clothing looseness (Issenman, 1997). Unless deliberately blocked, spaces exist under the loose clothing, and air movement by the "chimney effect" can therefore occur. In this way, the stage is set for extensive modulation of heat loss by use of drawstrings and sashes that control the intensity of the chimney effect. When the sash (belt) at the waist (Fig. 1) is not tightly tied, outside air can slowly enter at the lower margins of the parka and, becoming warm, rise to the neck and exit, carrying heat and moisture along with it (Folk, 1966, provides a diagram). If the sash is tied more tightly around the waist, this airflow can be impeded, allowing body heat to accumulate under the parka (thereby reducing heat loss even though, as shown in Figures $2 \mathrm{a}$ and $2 \mathrm{~d}$, compression of the parka by the tight sash may facilitate heat loss through the parka skins). Similarly, boots, mittens, and hood may be equipped with ties that can be loosened or tightened to control local chimney effects. Issenman (1997) reports that men's parkas sometimes are made with side slits (not present in our parkas) that can be opened or closed.

Layering: For many observers, the method of clothing modulation that is simplest to understand is layering (Rodahl, 1958; Issenman, 1997). To reduce heat retention, one or both skins of the hood can be pulled off the head. Moreover, a hunter typically travels with a sled and thus can take off one of the parka skins if desired, carrying it on the sled until needed again. Because the two parka skins may differ in insulation, the hunter might also modulate insulation by his choice of which skin to wear when he removes a skin. These points explain why the two skins of the parka are not attached to each other.

Moving arms in or out of sleeves: Because of the loose construction of the sleeves, a hunter can readily pull his arms out of the sleeves and position them under the main body of his parka, where he can hold his hands and arms against his torso for warmth (Rodahl, 1958; King, 2005).

Matching metabolic heat production and clothing insulation: Rodahl (1958) emphasizes that northern people walk at a pace at which metabolism produces heat just fast enough to stay warm, and they do so with great stamina. The rate of metabolic heat production must, if possible, be held within a certain range: sufficient to stay warm, but never high enough to cause sweating within the clothing (Moran, 1981). The entire burden of achieving this state does not fall on the clothing, because metabolic heat production is also modulated to these ends. A significant point stressed by Folk (1966) is that some auto-control occurs because vigorous body movements not only increase the rate of heat production but also increase the rate of heat loss by inducing "pumping" of air through spaces under the clothing.

As the preceding paragraphs indicate, there are countless fascinating and important questions for thermal physiologists to address in understanding how a person can be abroad on the Arctic landscape for long periods (even many days), always in a single set of clothing.

We hope that our findings in this paper, obtained from the perspective of thermal physiologists, set the stage for and encourage future research led by and in partnership with northern peoples, who alone know how to produce, wear, and communicate the essential value of caribou-skin clothing.

\section{ACKNOWLEDGEMENTS}

We thank Jill Oakes for providing access to the caribou-skin clothing we studied. Few have done more than Jill to promote understanding of Inuit clothing, and we are honored to be recipients of her assistance. We also thank Emmelia Wiley at the Centre for Earth Observation Science (University of Manitoba) for her exceptional assistance with organizing and facilitating our use of the remarkable low-temperature research facility at the Centre. Jacob Kimmel helped with logistic preparations. 


\section{REFERENCES}

Burton, A.C., and Edholm, O.G. 1955. Man in a cold environment: Physiological and pathological effects of exposure to low temperatures. London: Edward Arnold.

Campbell, G.S., and Norman, J.M. 1998. An introduction to environmental biophysics, 2nd ed. New York: Springer Science+Business Media.

https://doi.org/10.1007/978-1-4612-1626-1

Cena, K., and Clark, J.A. 1978. Thermal insulation of animal coats and human clothing. Physics in Medicine and Biology 23(4):565-591.

https://doi.org/10.1088/0031-9155/23/4/001

Cotel, A.J., Golingo, R., Oakes, J.E., and Riewe, R.R. 2004. Effect of ancient Inuit fur parka ruffs on facial heat transfer. Climate Research 26:77-84. https://doi.org/10.3354/cr026077

Cuyler, C., and Øritsland, N.A. 2004. Rain more important than windchill for insulation loss in Svalbard reindeer fur. Rangifer 24(1):7-14.

https://doi.org/10.7557/2.24.1.262

Folk, G.E., Jr. 1966. Introduction to environmental physiology: Environmental extremes and mammalian survival. Philadelphia: Lea and Febiger.

Hammel, H.T. 1955. Thermal properties of fur. American Journal of Physiology 182(2):369-376.

https://doi.org/10.1152/ajplegacy.1955.182.2.369

Issenman, B.K. 1997. Sinews of survival: The living legacy of Inuit clothing. Vancouver: University of British Columbia Press.

Johnsen, H.K., Rognmo, A., Nilssen, K.J., and Blix, A.S. 1985. Seasonal changes in the relative importance of different avenues of heat loss in resting and running reindeer. Acta Physiologica Scandinavica 123(1):73-79. https://doi.org/10.1111/j.1748-1716.1985.tb07563.x

King, J.C.H. 2005. Introduction. In: King, J.C.H., Pauksztat, B., and Storrie, R., eds. Arctic clothing of North AmericaAlaska, Canada, Greenland. Montreal: McGill-Queens University Press. 12-22.

King, J.C.H., Pauksztat, B., and Storrie, R., eds. 2005. Arctic clothing of North America-Alaska, Canada, Greenland. Montreal: McGill-Queens University Press.

Meeks, N.D., and Cartwright, C.R. 2005. Caribou and seal hair: Examination by scanning electron microscopy. In: King, J.C.H., Pauksztat, B., and Storrie, R., eds. Arctic clothing of North America-Alaska, Canada, Greenland. Montreal: McGill-Queens University Press. 42-44.

Monteith, J.L., and Unsworth, M.H. 2013. Principles of environmental physics, 4th ed. Oxford: Academic Press.

Moran, E.F. 1981. Human adaptation to Arctic zones. Annual Review of Anthropology 10:1-25. https://doi.org/10.1146/annurev.an.10.100181.000245

Oakes, J. 1992. Comparison of factors influencing Caribou and Copper Inuit skin clothing. Dress 19(1):47-56. https://doi.org/10.1179/036121192805298391
Oakes, J., and Riewe, R. 1998. Spirit of Siberia: Traditional Native life, clothing, and footwear. Washington, D.C.: Smithsonian Institution Press.

Oakes, J., Wilkins, H., Riewe, R., Kelker, D., and Forest, T. 1995. Comparison of traditional and manufactured cold weather ensembles. Climate Research 5:83-90. https://doi.org/10.3354/cr005083

Pavlov, P., Svendsen, J.I., and Indrelid, S. 2001. Human presence in the European Arctic nearly 40,000 years ago. Nature 413:64-67. https://doi.org/10.1038/35092552

Pedersen, K. 2005. Eskimo sewing techniques in relation to contemporary sewing techniques-Seen through a copy of a Qilakitsoq costume. In: King, J.C.H., Pauksztat, B., and Storrie, R., eds. Arctic clothing of North America-Alaska, Canada, Greenland. Montreal: McGill-Queens University Press. 70-73.

Pharand, S. 2012. Caribou skin clothing of the Igloolik Inuit. Iqaluit: Inhabit Media.

Rodahl, K. 1958. Human acclimatization to cold. In: Ferrer, M.I., ed. Transactions of the $5^{\text {th }}$ Conference on Cold Injury, 10-15 March 1957, Ladd Air Force Base, Alaska. New York: Josiah Macy, Jr. Foundation. 177-252.

Scholander, P.F., Walters, V., Hock, R., and Irving, L. 1950. Body insulation of some Arctic and tropical mammals and birds. Biological Bulletin 99(2):225-236. https://doi.org/10.2307/1538740

Scholander, P.F., Andersen, K.L., Krog, J., Lorentzen, F.V., and Steen, J. 1957. Critical temperature in Lapps. Journal of Applied Physiology 10(2):231-234.

https://doi.org/10.1152/jappl.1957.10.2.231

Tattersall, G.J. 2016. Infrared thermography: A non-invasive window into thermal physiology. Comparative Physiology and Biochemistry, Part A: Molecular and Integrative Physiology 202:78-98.

https://doi.org/10.1016/j.cbpa.2016.02.022

Timisjärvi, J., Nieminen, M., and Sippola, A.-L. 1984. The structure and insulation properties of the reindeer fur. Comparative Biochemistry and Physiology, Part A: Physiology 79(4):601-609. https://doi.org/10.1016/0300-9629(84)90456-0

Velichko, A.A., Vasil'ev, S.A., Gribchenko, Y.N., and Kurenkova, E.I. 2017. Stages of the initial human colonization of Arctic and Subarctic. Chapter 11. In: Kotlyakov, V.M., Velichko, A.A., and Vasil'ev, S.A., eds. Human colonization of the Arctic: The interaction between early migration and the paleoenvironment. London: Academic. 507-530. https://doi.org/10.1016/B978-0-12-813532-7.00024-3

Watkins, S.M., and Dunne, L.E. 2015. Functional clothing design: From sportswear to spacesuits. New York: Fairchild Books (Bloomsbury Publishing). 